\title{
Impacto de la envolvente en la demanda de energía en calefacción residencial de la región metropolitana de La Plata, tomando como caso testigo el reciclado energético de una vivienda
}

Impact of the envelope on residential heating energy demand in the Metropolitan Region of La Plata, based on the energy retrofit of a house

\begin{tabular}{r}
\hline \\
Universidad Nacional de La Plata \\
La Plata - Argentina \\
Recebido em 18/03/15 \\
Aceito em 07/08/15 \\
Universidad Nacional de La Plata \\
La Plata - Argentina \\
Universidad Nacional de La Plata \\
La Plata - Argentina \\
Gabriela Reus Netto \\
María de la Paz Diulio \\
La Plata - Argentina
\end{tabular}

\section{María de la Paz Diulio \\ Gabriela Reus Netto \\ Roberto Berardi \\ Jorge Daniel Czajkowski}

\section{Resumen}

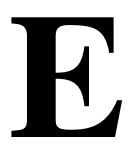

1 área metropolitana de La Plata representa el 1,6\% de las viviendas de la Argentina. A partir del análisis del reciclado de una vivienda se construyen indicadores básicos con el fin de proponer una metodología que facilite la extrapolación, a nivel regional, del impacto que causaría un programa de eficiencia energética en viviendas. Se exponen desde el nivel micro a macro los resultados obtenidos en un contexto de carestía energética y recurrentes crisis en la oferta de combustibles y electricidad en la Argentina. La mejora en la resistencia térmica de muros y techos en todo el parque residencial de La Plata conllevaría a una reducción del 12\% de la energía consumida en calefacción, y un ahorro de 30.000 TEP/año. Se concluye que la incidencia que implica la colocación de aislación adicional respecto del costo de la construcción justifica su uso, resolviendo parcialmente la falta de combustibles en el país, reduciendo gastos fijos en la vivienda, otorgando confort térmico a los usuarios y generando reactivación del sector de la construcción.

Palablas-claves: Eficiencia energética. Confort térmico. Aislación térmica. EIFS. AuditCad.

\section{Abstract}

The metropolitan area of La Plata, Argentina, represents $1.6 \%$ of households in Argentina. Based on the analysis of the energy retrofit of a house, we provide indicators in order to propose a methodology that facilitates the extrapolation, at regional level, of the impact of a general energy retrofit in homes. The results obtained are presented from micro to macro level, in context of energy shortage and recurrent crisis in the supply of fuels and electricity in Argentina. The improved thermal resistance of walls and ceilings throughout the residential park of La Plata lead to a reduction of $12 \%$ of the energy consumed in heating, and a saving of 30,000 TEP / year. We conclude that the incidence of additional insulation on the cost of building justifies its use, partially solving the lack of fuel in our country, reducing fixed costs in housing, providing thermal comfort to users and generating economic reactivation of the construction sector.

Keywords: Energy efficiency. Thermal comfort. Thermal insulation. EIFS. AuditCad. 


\section{Introducción}

La deficiencia energética en la Argentina, derivada de la escasa disponibilidad y del elevado consumo, es una problemática que viene incrementándose, principalmente cuando analizamos que en el año de 2013, según la información pública disponible, los gastos de importación de gas natural, licuado y combustibles llegaron a 12.800 millones de dólares y que solamente en el primer semestre de 2014 se importaron aproximadamente cuatro veces más energía que en todo el año de 2013 (OVIEDO, 2014).

En este contexto, el conjunto de usuarios compuesto por el sector residencial, el sector comercial y los entes oficiales consumen el $30 \%$ del gas natural, y en invierno representan el $60 \%$ del consumo de gas (TANIDES et al., 2013; GIL, 2013). Sin embargo, de acuerdo con auditorías energéticas realizadas (CZAJKOWSKI et al., 2012) esta fracción elevada de consumo no alcanza a satisfacerlas necesidades de confort de los residentes, es decir que tanto la eficiencia de los sistemas de climatización como la capacidad de las viviendas de conservar el calor es baja.

Desde el punto de vista medioambiental, social y económico; y también político sería conveniente subsidiar mejoras en la eficiencia térmica de los edificios antes que continuar subsidiando la energía. Esto se debe a que aislando térmicamente se puede reducir la carga térmica de calefacción hasta un $50 \%$ con otras ventajas comopromover la actividad económica, mejorar el confort, reducir el impacto ambiental y evitar los cortes a otros usuarios (BOURGES; GIL, 2014).

Por lo tanto los profesionales de la construcción tienen un amplio campo de trabajo en cuanto al incremento de la eficiencia energética de los edificios, a fin de minimizar la demanda energética y mejorar la calidad de vida de los usuarios.

Desde el sector de la distribución de combustible también muestran intenciones de detectar los sectores de consumo que evidencian un ahorro potencial significativo. Han realizado estudios que intentan modificar los cuadros tarifarios que inciten a reducir el consumo sin afectar a los usuarios de ingresos bajos. Esto se resolvería determinando una línea base de consumo esperado que dependa de los grados días de calefacción de la localidad, y a partir de esta línea se determinan las diferentes categorías (GIL; PRIETO, 2013).

Este trabajo toma como caso de estudio una vivienda unifamiliar habitada por 4 integrantes, que para reducir el usode recursos no renovables deciden invertir en mejorar la envolvente térmica. Detectado el ahorro en el caso testigo, se extrapola al parque habitacional residencial de la región metropolitana de La Plata para predecir el ahorro potencial en caso de que todas las viviendas efectuaran una mejora similar.

El tipo de vivienda exenta analizada es de baja compacidad y desarrollada en planta baja. En etapas sucesivas a través del tiempo se proponen alcanzar progresivamente diferentes niveles de sustentabilidad. Esta cuestión también fue estudiada por otros autores (VERBEEK; HENS, 2005) quienes afirman que las medidas de ahorro energético pueden implementarse en diferentes etapas e independientemente una de otra, y proponen una jerarquía de acuerdo con la eficacia de las medidas:
(a) 1 = aislación del techo;
(b) 2 = aislación del piso, si fuera posible acceder;
(c) $3=$ mejora térmica en el comportamiento de los vidrios, casi siempre deben reemplazarse los marcos;

(d) 4 = mejora en la eficiencia energética de los sistemas de climatización; y

(e) $5=$ incorporación de energías renovables.

El objetivo de este trabajo es evaluar desde un enfoque técnico y económico el mejoramiento energético de una vivienda unifamiliar con el fin de alcanzar eficiencia energética progresiva, así como predecir el beneficio que implicaría a nivel regional este tipo de estrategias.

Entre otros, en el trabajo se analiza y discute:

(a) las características tecno-económicas del reciclado energético edilicio;

(b) la valoración del incremento de confort térmico producido por las mejoras realizadas;

(c) la cuantificación del ahorro energético luego de la mejora térmica de la envolvente junto al análisis del consumo histórico de gas;

(d) la cuantificación del ahorro generado bajando un grado la temperatura de set point del termostato del sistema centralizado de climatización por aire, así como el significado de dicha reducción en la satisfacción del usuário; y

(e) estimación del impacto del reciclado energético generalizado en la región y reflexiones acerca de los primeros efectos de un cambio climático. 


\section{Metodología}

El trabajo se propone aclarar el contexto regional de uso final de la energía e implementar el reciclado energético de una vivienda al menor costo posible por metro cuadrado, con el fin de generar conocimiento para construir indicadores. Estos indicadores vuelven a ser aplicados al contexto regional y evalúan el impacto estimado que puede alcanzarse.

Las mejoras realizadas en el edificio, fueron concebidas con el concepto de eficiencia energética progresiva. La vivienda analizada es una construcción tradicional materializada en el año 2000 con muros de ladrillos cerámicos huecos de $18 \mathrm{~cm}$ revocados en ambas caras, cubierta de chapa de zinc y machimbre, y ventanas con marco de chapa y vidrio simple. A pesar de hacer un cuidadoso uso de la energía las facturas durante el período invernal eran muy elevadas, junto a una insatisfacción térmica en el confort; esto llevó a que el propietario decidiera implementar progresivamente mejoras térmicas. Dichas mejoras se propusieron en 3 etapas, a saber:

(a) primera etapa: aislación de los cielorrasos en los sectores de las cubiertas de chapa, mediante lana de vidrio, y placas machihembradas de PVC flexible. Aislación en los muros externos de la zona de dormitórios;

(b) segunda etapa: aislación en el total de la envolvente; $\mathrm{y}$

(c) tercera etapa: colocación de doble vidrio en puertas y ventanas.

La vivienda se encuentra en Manuel B. Gonnet, partido de La Plata, a una latitud de $34,8^{\circ} \mathrm{S}$ y 8 msnm. El clima es templado cálido húmedo, sub zona IIIB. Los veranos son suaves con una temperatura máxima media de $28,5^{\circ} \mathrm{C}$ e inviernos poco rigurosos (Figura 1), con temperaturas mínimas de $6,7^{\circ} \mathrm{C}$. La humedad promedio es alta, entre 71 y $86 \%$. (INSTITUTO..., 2012).
La vivienda tiene $175 \mathrm{~m}^{2}, 3$ dormitorios, un estudio, estar-comedor, cocina y dependencias. Se implanta en un lote en esquina con un partido arquitectónico en "L" completamente resuelto en planta baja. El entorno es de baja densidad, con viviendas extendidas en planta baja, generalmente despegadas del perímetro del lote. Todos los ambientes, excepto el estudio, reciben sol directo porque sus aberturas están orientadas al noreste y noroeste.La relación entre superficie envolvente (muros y cubierta) y superficie a calefaccionar es $2,47 \mathrm{~m}^{2} / \mathrm{m}^{2}$, que por ser mayor a $2 \mathrm{~m}^{2} / \mathrm{m}^{2}$ puede definirse como no-compacta (GELARDI; ESTEVES, 2010).

Las paredes, en su versión original, son de ladrillo cerámico hueco revocado en ambas caras, con un espesor de $21 \mathrm{~cm}$, la cubierta es de chapa con $1 \mathrm{~cm}$ de lámina de polietileno aluminizado con encapsulado de burbujas de $10 \mathrm{~mm}$ a modo de aislante térmico y las aberturas son de chapa doblada $\mathrm{n}^{\circ} 18$ con vidrio $5+5$.

En el mes de marzo de 2014 se completó la aislación en la cubierta (Figura 2), que consistió en incorporar $10 \mathrm{~cm}$ de lana de vidrio en la cara interior, debajo del cielorraso, sostenida por machimbre de PVC flexible.

Para la mampostería exterior, realizada en mayo de 2014, se utilizó la técnica conocida como EIFS (Figura 3), que proviene del inglés Exterior Insulation and Finish System que significa sistema de aislación y terminación exterior. Consiste en incorporar una capa adicional de aislación térmica de poliestireno expandido (EPS) en la cara exterior de los muros, sujetada con tornillos y arandelas, a la que se le aplica una capa de $8 \mathrm{~mm}$ de mortero tipo base coat "Iggam" que protege y rigidiza la malla de fibra de vidrio de $90 \mathrm{grs} / \mathrm{m}^{2}$ y $0.5 \mathrm{~cm}$ $\mathrm{x} 0.5 \mathrm{~cm}$. Luego puede agregarse cualquier tipo de acabado texturado, proyectado o con llana, o pintura (Figuras 4, 5 y 6).

\section{Figura 1 - Ubicación de la vivienda en la Ciudad La Plata}

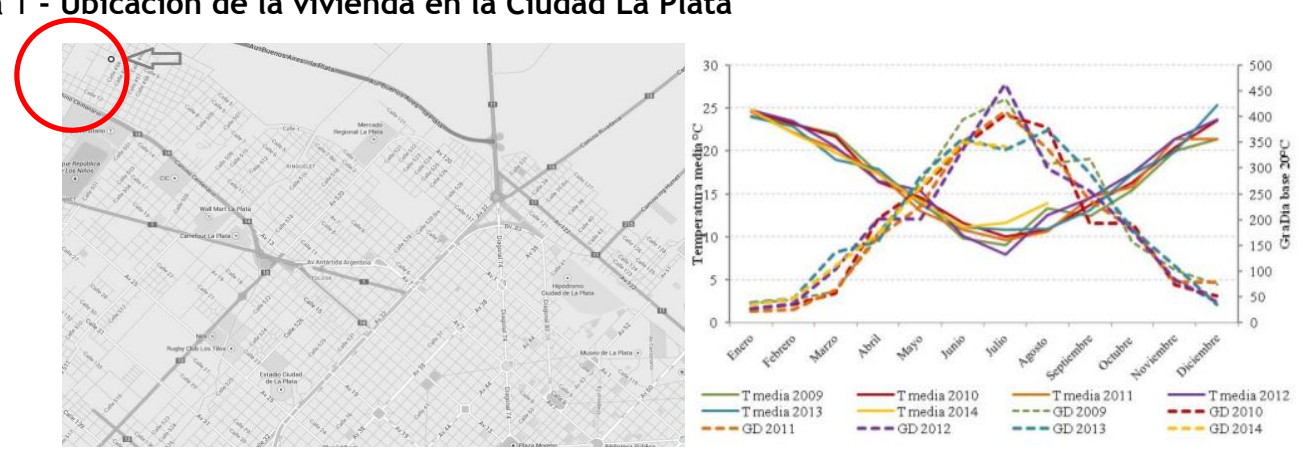

Fuente: Google Maps (2014).

Nota: temperatura media y grados día base $20^{\circ} \mathrm{C}$ reales del sitio. 
Figura2 - Detalle de techo con y sin aislación

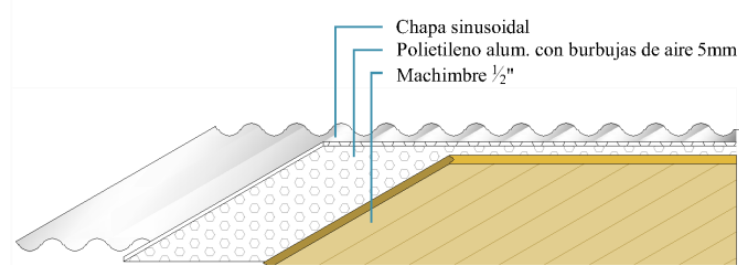

Figura 3 - Detalle muro sin y con EIFS

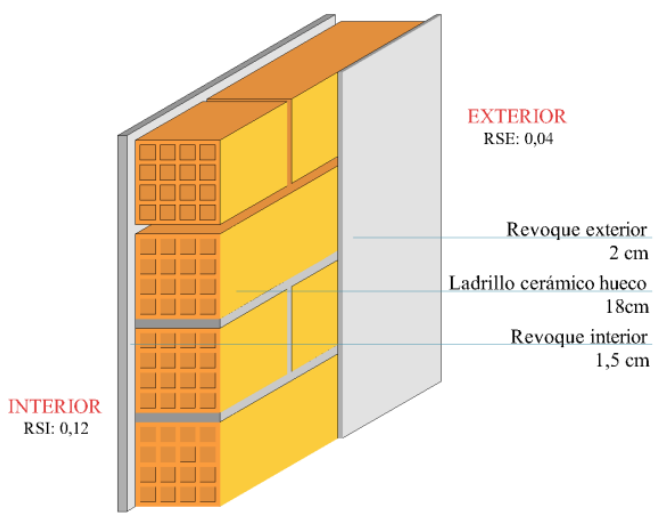

El conjunto posee buena resistencia mecánica y de acuerdo a la bibliografía su resistencia térmica se verifica aún después de 20 años de colocado (STAZI; DI PERNA; MUNAFÓ, 2009).

El sistema de climatización es central por aire a gas natural. Consta de un equipo calefactor Goodman de $24000 \mathrm{Kcal} / \mathrm{h}$ y una máquina enfriadora Goodman, y el tendido de la cañería de distribución se realiza mediante conductos de chapa a la vista de sección circular con aislación térmica interna.

En cuanto a ocupación, la familia se compone de 4 personas que hacen uso intensivo de la vivienda sábados y domingos mientras que de lunes a viernes la ocupación se reduce en horario escolar y laboral, permaneciendo vacía de 12 a 17hs. La calefacción se enciende a demanda de los usuarios. Generalmente se utiliza 8 horas por día promedio, entre las 19:00hs y las 23:00hs y de 6:00 a 9:00hs en días laborables y de modo más flexible en fines de semana.

Los paños vidriados orientados al norte están provistos de cortinas de tipo black out. Durante el día en invierno se aprovecha la radiación solar como ganancia directa, y por las tardes se cierran para disminuir pérdidas. La zona diurna de la vivienda es el living, que posee ganancia solar significativa, posee grandes aberturas al noreste protegidas con una pérgola, y una tira de paños
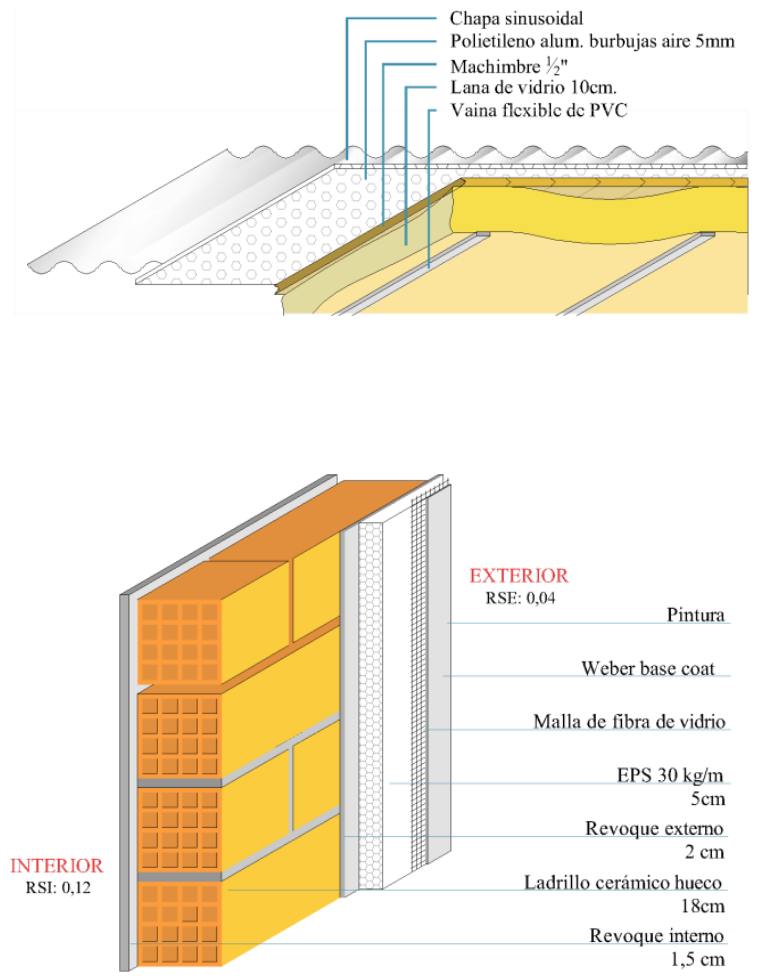

fijos con doble vidriado hermético (DVH) sin protección a modo de clerestorio cenital. La zona nocturna tiene las aberturas orientadas hacia el sudeste y al noroeste. Las aberturas orientadas al noroeste tienen una tira similar a la del estar de paños fijos con DVH.La otra zona evaluada de la vivienda es el estudio, con aberturas al sudeste y al sudoeste, que no es frecuentada habitualmente dado que no es confortable térmicamente.

En la evaluación del confort térmico luego del reciclaje se utilizaron 3 dataloggers Hobo UX100003 con 3,5\% de precisión para el interior de la vivienda y para control del clima exterior el sensor de temperatura y humedad relativa exterior $\mathrm{HOBO}$ U23-001 Pro v2, con un rango de $-40^{\circ}$ a $70^{\circ} \mathrm{C}$ y RH: $0-100 \%$. La precisión es de $\pm 0.21^{\circ} \mathrm{C}$ entre $0^{\circ}$ y $50^{\circ} \mathrm{C}$ y $\pm 2.5 \%$ entre $10 \%$ y $90 \%$ con resguardo meteorológico. Además se utilizó la información de la estación meteorológica Davis Vantage Pro2, y los datos de temperaturas medias mensuales, grados días con base $20^{\circ} \mathrm{C}$ mensuales desde 2008 hasta la actualidad (Figura 1).

El sensor 1 se colocó en el estudio, ubicado al sur de la vivienda, con aberturas orientadas al sudoeste y al sudeste. Es el sector de la vivienda en el que no se han realizado ningún tipo de mejoras a la envolvente. Es una habitación poco utilizada por lo que se desprecian las ganancias térmicas por ocupación. El sensor 2 se colocó en la sala de estar. En este sector de la vivienda se aisló 
térmicamente la cubierta con $10 \mathrm{~cm}$. de lana de vidrio. El sensor 3 ocupó la zona de dormitorios, donde se colocó el EIFS y la aislación en cubierta. Los sensores fueron programados para registrar datos de temperatura y humedad relativa cada 30 minutos entre el 17 de julio y el 4 de agosto de 2014.

Antes de comenzar la experiencia se colocó el termostato a $21^{\circ} \mathrm{C}$. Para registrar el consumo energético se tomó notación del medidor de gas el día 17 de julio a las 00 hs y se repitió la operación luego de 5 días. Se cambió la temperatura de setpoint a $20^{\circ} \mathrm{C}$ y se dejaron transcurrir dos días completos hasta que en los tres sensores se observaron temperaturas inferiores a la de base. Una vez restablecido el régimen inicial, calculado entre 3 y 4 horas según las características de la envolvente (YAÑEZ, 1982), comenzó el segundo ciclo de medición.

\section{Figura 4 - Detalle de malla de fibra de vidrio con base coat}

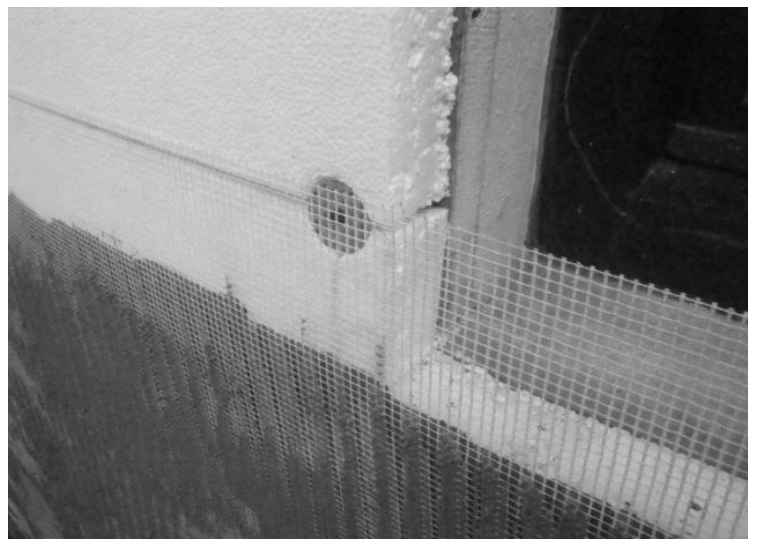

Figura 5 - Colocación de EPS en la cara este

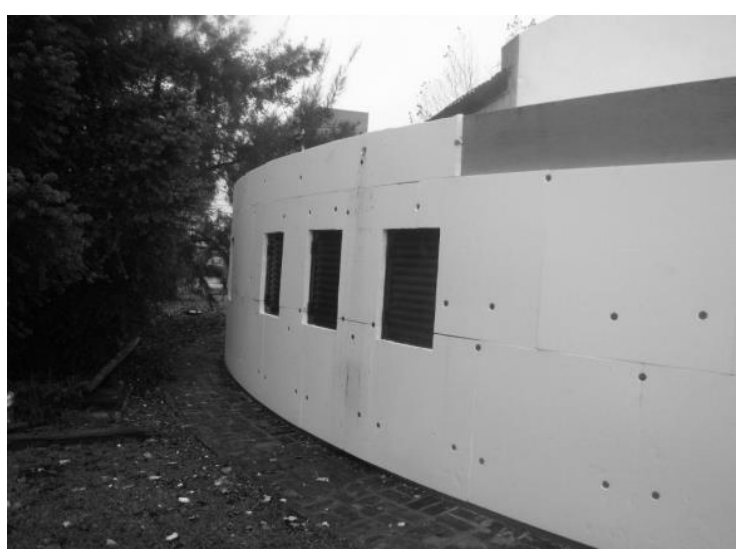

Figura6 - Volumetría, vista noreste con sombras correspondientes al mediodía

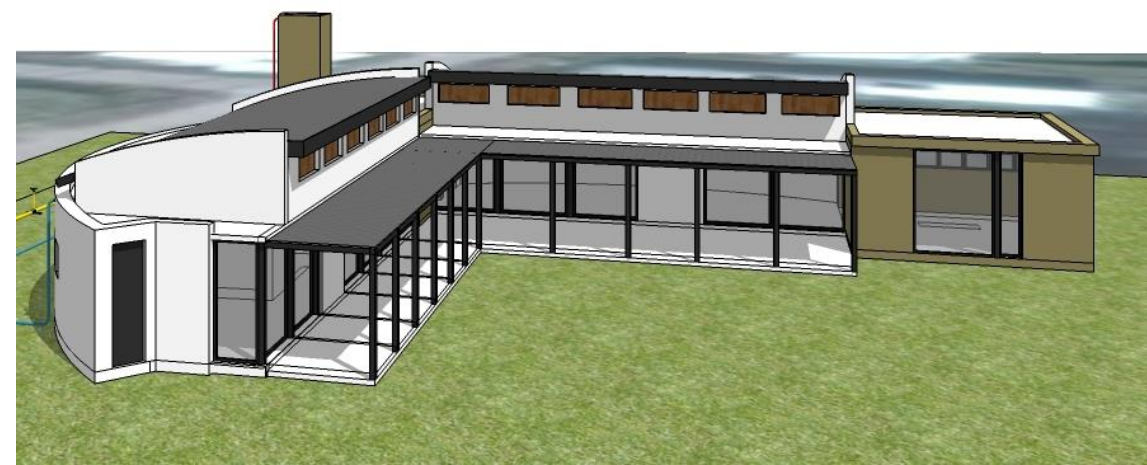


El 24 de julio se registró medidor de gas y nuevamente el 28 de julio a última hora. El último registro se realizó el 4 de agosto para conocer el consumo sin ningún tipo de restricción al termostato.

\section{Resultados}

\section{Verificación del riesgo de condensación en muros}

Utilizando el programa CEEMACON (GONZALO et al., 2000) se calculó la verificación del riesgo de condensación intersticial según la normativa argentina (INSTITUTO..., 2000), a fin de determinar la temperatura superficial interior en muros.

En la Figura 7 puede verse el análisis en la solución de muro original y la mejora, donde la temperatura superficial interior pasa de $13,44^{\circ} \mathrm{C}$ a $16,83^{\circ} \mathrm{C}$ con la incorporación de $5 \mathrm{~cm}$ de EPS en la cara exterior.

\section{Análisis técnico-económico de las mejoras}

La inversión realizada en la mejora de la cubierta fue de $\$ 232 / \mathrm{m}^{2}$, neto (materiales y mano de obra, excluyendo fletes, honorarios profesionales y cargas sociales). La mejora en la calidad térmica de la envolvente fue del $90 \%$, pasando de un $\mathrm{K}=$ $3,64 \mathrm{~W} / \mathrm{m}^{2} \mathrm{~K}$ en la versión original (chapa pre pintada color, polietileno aluminizado con burbujas de aire y machimbre de $1 / 2$ ") a un $\mathrm{K}=$ $0,37 \mathrm{~W} / \mathrm{m}^{2} \mathrm{~K}$ (solución original $+10 \mathrm{~cm}$ de lana de vidrio + machimbre de PVC).

La inversión realizada para la mejora térmica de muros fue de $\$ 258 / \mathrm{m}^{2}$ neto. El sistema constructivo sufrió una mejora del $70 \%$ pasando de tener una transmitancia térmica de $1,50 \mathrm{~W} / \mathrm{m}^{2} \mathrm{~K}$ a $0,44 \mathrm{~W} / \mathrm{m}^{2} \mathrm{~K}$ con la mejora de EIFS, a partir de la incorporación de $5 \mathrm{~cm}$ de EPS de $30 \mathrm{Kg} / \mathrm{m}^{3}$.

$\mathrm{Si}$ se comparan los valores de transmitancia térmica con los máximos admisibles indicados por la Ley 13059/03 (BUENOS..., 2003) y su Decreto reglamentario 1030 (BUENOS, 2010) de la Provincia de Buenos Airesque se refiere al conjunto de Normas IRAM sobre acondicionamiento térmico de edificios, para la temperatura exterior de diseño de $-2,4^{\circ} \mathrm{C}$, se advierte que la cubierta original no alcanza a verificar nivel $\mathrm{C}$, cuyo máximo admisible es 1
$\mathrm{W} / \mathrm{m}^{2} \mathrm{~K}$, y luego de la mejora se acerca al nivel A $\left(\mathrm{K}=0,296 \mathrm{~W} / \mathrm{m}^{2} \mathrm{~K}\right)$. En el caso del muro, la versión original alcanzaba a cumplir el nivel $\mathrm{C}$, y luego de la mejora, también está cerca de alcanzar el nivel A $\left(\mathrm{K}=0,342 \mathrm{~W} / \mathrm{m}^{2} \mathrm{~K}\right)$ (BUENOS..., 2003, 2010).

En la Figura 8 queda evidenciado el efectivo resultado del aislamiento, cuando verificamos que antes de la intervención, las mayores pérdidas térmicas eran responsabilidad de la cubierta, cuyo valor se redujo de $455 \mathrm{~W} /{ }^{\circ} \mathrm{C}$ a $259 \mathrm{~W} /{ }^{\circ} \mathrm{C}$. En los muros, debido a la pequeña superficie intervenida, la reducción es menor, de $25 \mathrm{~W} /{ }^{\circ} \mathrm{C}$. Con estas modificaciones las ventanas pasan a representar el mayor porcentaje de pérdidas, siendo este sector la próxima etapa a reciclar.

\section{Análisis del confort térmico luego del reciclaje}

Finalizada la primera etapa de eficiencia energética progresiva de la vivienda, el usuario fijó la temperatura del termostato en $20^{\circ} \mathrm{C}$ cuando antes era necesario ubicarlo a $24^{\circ} \mathrm{C}$. Esta es la primera manifestación positiva del mejoramiento, junto a la reducción de corrientes convectivas percibidas por los usuarios; con el ascenso de la temperatura superficial interior de los muros exteriores mejorados térmicamente. La temperatura superficial interior de muros exteriores en sector dormitorios pasó de $13,4^{\circ} \mathrm{C}$ a $16,8^{\circ} \mathrm{C}$ tal como se muestra en la Figura 7.

Esta reducción se corrobora mediante la toma de datos con un termómetro infrarrojo a las 6:00hs, momento del día en el que generalmente ocurren las temperaturas mínimas absolutas. En esta condición, la temperatura superficial interior de los muros con aislación térmica fue de $17^{\circ} \mathrm{C}$, mientras que en las paredes sin intervención fue de $11^{\circ} \mathrm{C}$. La temperatura superficial de la cara exterior de todos los muros fue de $3^{\circ} \mathrm{C}$, mostrando una diferencia de $14^{\circ} \mathrm{C}$ en el muro intervenido.

La mejora realizada en la vivienda resulta satisfactoria para los usuarios debido a que el calefactor funciona durante menos tiempo. Obviamente esto redunda en la reducción del consumo de gas, pero además mejora el descanso de los habitantes al reducir el ruido que genera a la noche el encendido del equipo. 
Figura 7 - Temperatura superficial interior y riesgo de condensación pre y post intervención
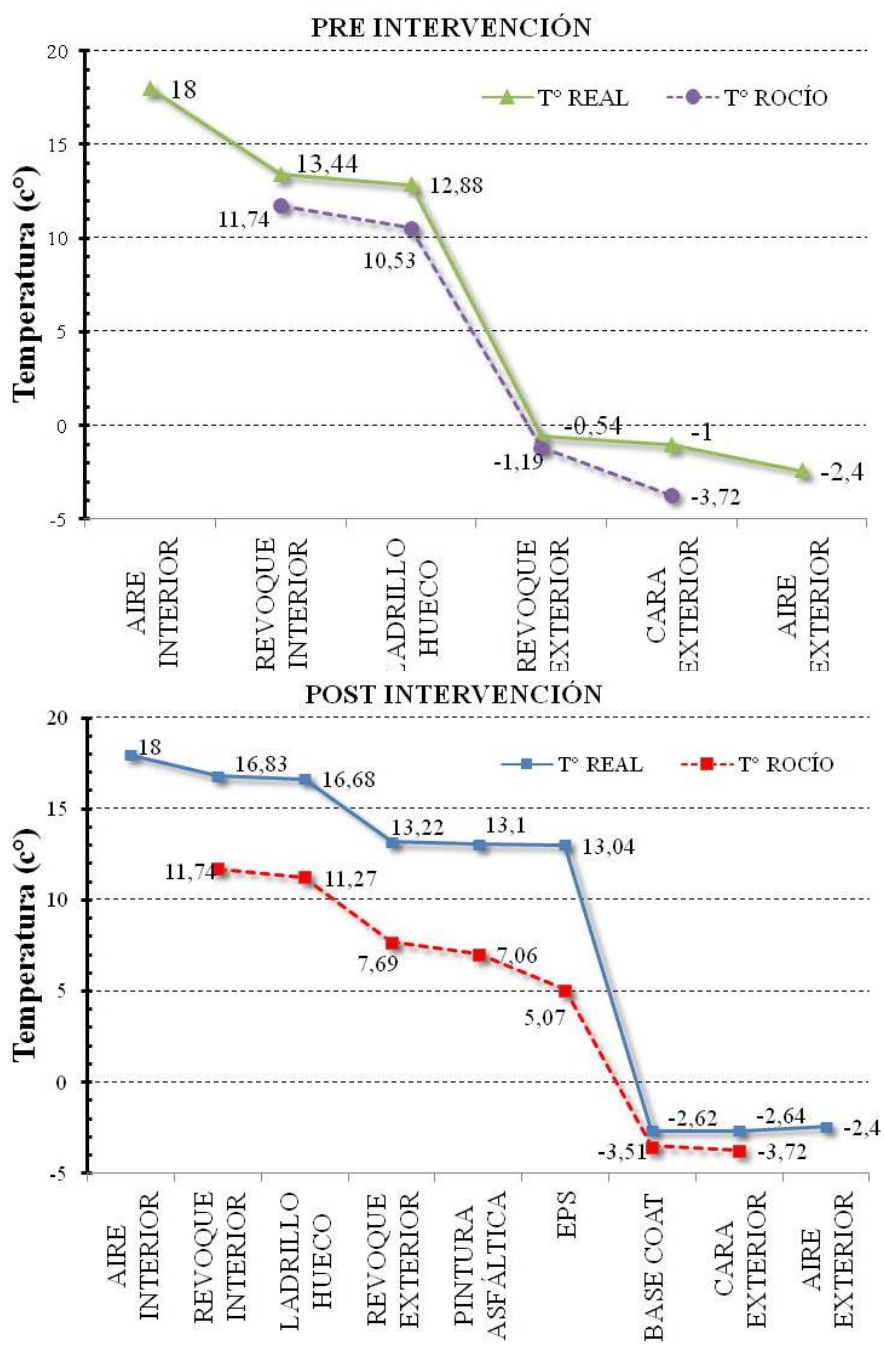

Fuente: elaboración propia sobre CEEMACON (CONZALO, 2003).

Figura 8 - Pérdidas térmicas en la vivienda pre y post intervención según AuditCad

Pérdidas según tipo de envolvente

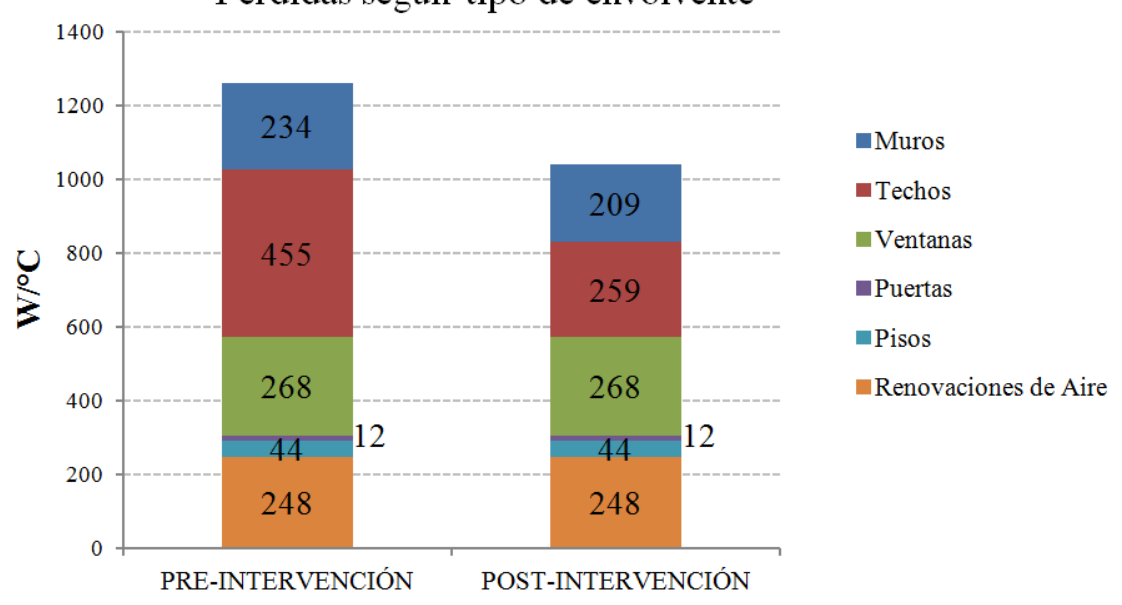


El climograma de Olgyay (1963) de la Figura 9 representa el monitoreo realizado con respecto a las condiciones de confort, y se ve en el ángulo inferior derecho la zona de estudio, bien compacta debido a la poca oscilación que se registra en el sector debido a la falta de uso del local, luego acercándose al centro en celeste la zona de dormitorios, con variaciones del $40 \%$ de la humedad relativa pero manteniendo temperaturas entre 18 y 23 en todo el período; y la zona estar, que se ve afectada por la ganancia solar que recibe pasado el mediodía, y gracias a la cual se han registrado momentos de temperatura interior de $36^{\circ} \mathrm{C}$, que de acuerdo con la percepción subjetiva del usuario, es considerada confortable en invierno.

En la Figura 10 se observa que en la zona de dormitorios y estar la temperatura es confortable tanto con el termostato a $21^{\circ} \mathrm{C}$ como a $20^{\circ} \mathrm{C}$. Esto no sucede en la zona estudio, en el sector sin mejora térmica de la casa, donde se produce un sensible descenso de la temperatura en el segundo periodo relacionado con una semana con menor temperatura media. Durante el tercer período, el usuario redujo el uso de la calefacción siguiendo sus propias necesidades de confort, regresando a su rutina de uso habitual.

\section{Análisis global del consumo de gas natural}

A partir de la información de las facturas bimestrales de gas de la vivienda, desde 2009 a 2014, se calculan los consumos mensuales para profundizar en la comprensión del encendido del equipo de calefacción, utilizando un procedimiento que transforma los registros bimestrales en valores mensuales, corrigiendo el desfasaje entre el períodode lectura y de facturación en Figura $11^{\mathrm{a}}$ (CZAJKOWSKI; CORREDERA; SAPOSNIK, 2003).Se muestran en la Figura 11 comparativamente los consumos respecto de seis años estudiados.

Se modeliza la vivienda mediante el AuditCad (CZAJKOWSKI, 1999) con el fin de determinar la carga térmica anual, carga térmica discriminada mensual, consumo potencial de gas natural en calefacción y contrastación con consumos auditados. La modelización se realiza en tres estadios:
(a) c1) comportamiento energético previo a las mejoras;

(b) c2) comportamiento energético con las mejoras actuales;

(c) c3) comportamiento energético con el total de muros y cubiertas aisladas; $y$

(d) c4) con muros y cubiertas aisladas y doble vidriado.

Figura 9 - Climograma de Olgyay sobre confort térmico

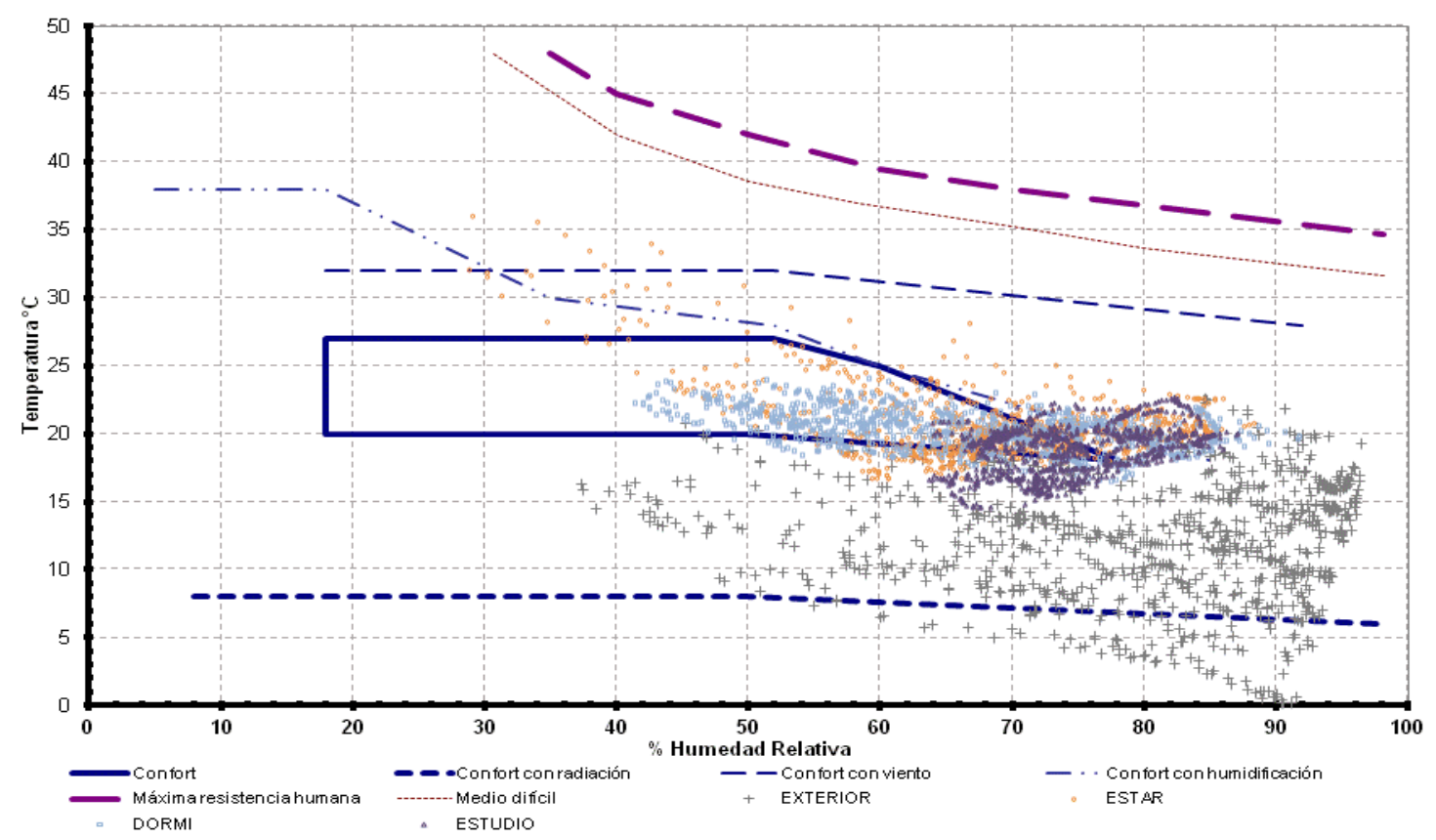

62 Diulio, M. de la P.; Reus Netto, G.; Berardi, R.; Czajkowski, J. D. 
Figura 10 - Monitoreo higrotérmico invernal

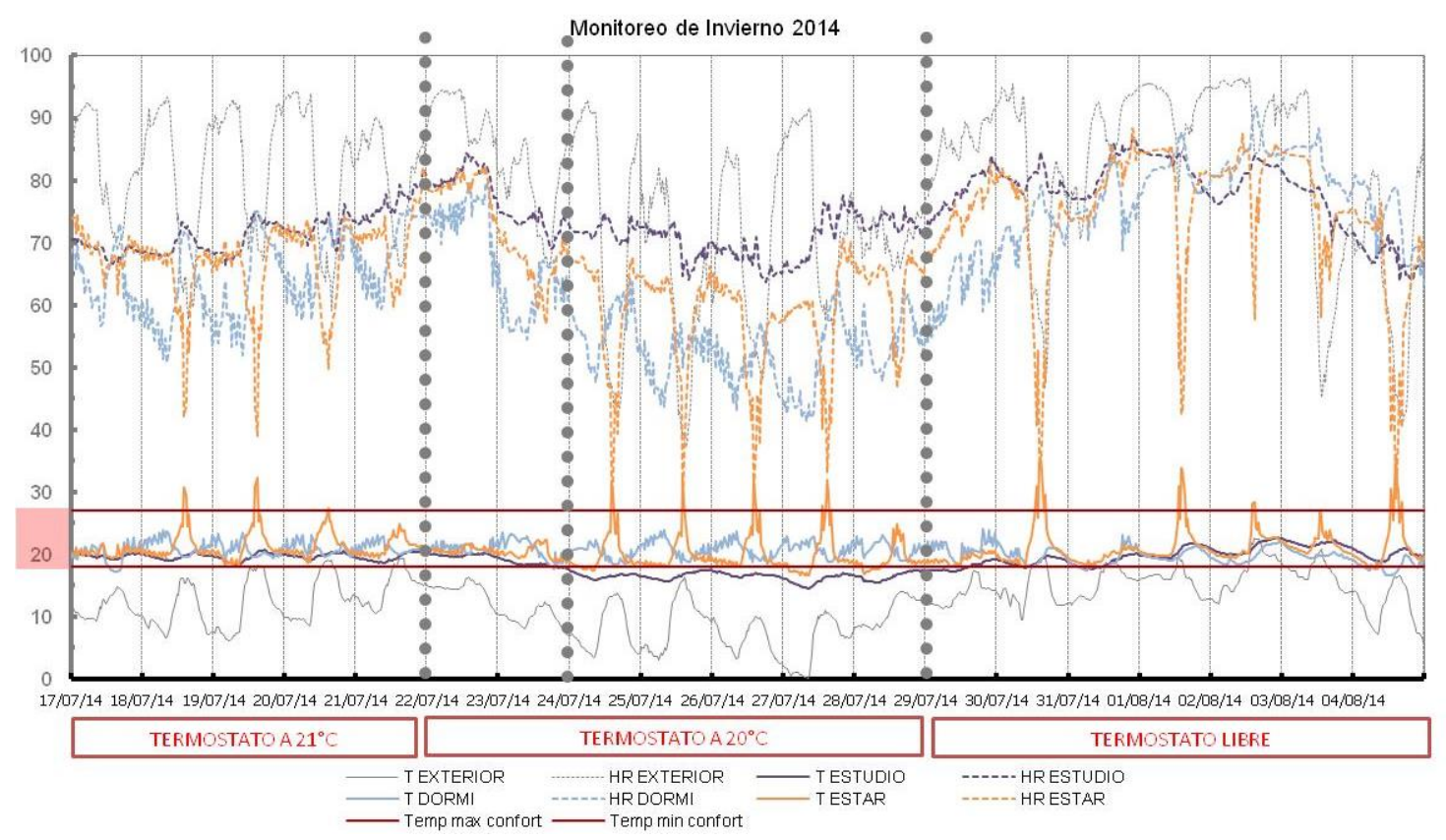

Habiendo realizado las modelizaciones, como se muestra en la Figura 11b, podemos verificar que la cantidad de $\mathrm{m}^{3}$ de gas necesario para calefaccionar la viviendaen su estado original es $2890 \mathrm{~m}^{3}$ al año para mantener un set point de $20^{\circ} \mathrm{C}$. Luego de la intervención que motivó el presente trabajo el consumo estimado se reduce a $2070 \mathrm{~m}^{3}$ al año, es decir, un $28 \%$ de ahorro. En caso de culminar con todas las mejoras previstas la demanda sería de $520 \mathrm{~m}^{3}$ al año, o un $82 \%$ de ahorro.

Cada punto de la Figura 12 representa un mes medido, y el color diferencia cada uno de los 6 años analizados. La tendencia hipotética normal de los puntos indica que a mayor valor de grados día en base $20^{\circ} \mathrm{C}\left(\mathrm{GD}_{20}\right)$ corresponde mayor consumo. Dado que la envolvente ha modificado su eficiencia, la línea de tendencia debería modificar su pendiente producto del mejor aprovechamiento de la energía. Esto se deberá verificar en futuras auditorías.

Comparando el comportamiento del invierno de 2014 con la mejora térmica con los años anteriores podemos inferir que la factura mostrará en el $4^{\circ}$ bimestre un consumo que será inferior, cuestión que no se verifica al presente debido a que en los años anteriores el equipo de climatización se encendía 8 hs/día y para la medición se encendió 24 hs/día.

Teniendo en cuenta esta situación y calculando el consumo horario de los 6 años analizados para el mes de julio, podemos ver (Tabla 1) que en 2014 el consumo de gas por hora $\left(\mathrm{m}^{3} / \mathrm{h}\right)$ de funcionamiento fue el $35 \%$ respecto a igual período del año 2013. Este consumo calculado se basa en los datos facturados que provee Camuzzi Gas Pampeana S.A., suponiendo que los intervalos de corte son los mismos.

En la Tabla 2 se resumen los consumos históricos, con los actuales durante el monitoreo. En los años 2009 y 2010, cuando la vivienda no contaba con mejoras térmicas en su envolvente, y haciendo un uso cuidado de la energía, es decir, encendiendo el equipo exclusivamente cuando se sentía frío, por la noche, el consumo promedio fue de $19,8 \mathrm{~m}^{3} /$ día, o $0,11 \mathrm{~m}^{3} / \mathrm{m}^{2}$.día. Buscando referencias en trabajos realizados en el país encontramos dos localizados en San Luis y La Plata, aunque solo se los toma como referencia sin mayor análisis debido a la disimilaridad en los tipos edilicios y situación climática. En el caso de San Luis corresponde a una vivienda unifamiliar con mejoras térmicas dando un consumo específico de gas natural de $0,024 \mathrm{~m}^{3} / \mathrm{m}^{2}$.día (FILIPPÍN; FOLLARI, 2003) y en departamentos en edificio en altura en casco urbano de La Plata un consumo específico de gas natural de 0,11 a $0,03 \mathrm{~m}^{3} / \mathrm{m}^{2}$.día (SALVETTI; CZAJKOWSKI; GÓMEZ, 2009).

Durante el invierno de 2014 la experiencia planteó 3 escenarios posibles, uno con el termostato fijo en $21^{\circ} \mathrm{C}$, otro con el termostato fijo en $20^{\circ} \mathrm{C}$ y otro dejando el termostato a libre disposición del usuario, es decir, a demanda.

En los 5 primeros días, con el equipo de calefacción encendido las 24 horas del día, la 
vivienda consumió $15,23 \mathrm{~m}^{3} /$ día de gas natural.Es decir que ya se evidencia una reducción de la demanda de energía para mantener constante una condición de termostato determinada (ver Tabla 2). En el segundo escenario, con termostato fijo a $20^{\circ} \mathrm{C}$ el consumo diario fue de $17,28 \mathrm{~m}^{3} /$ día. Este particular crecimiento se debe a que en la segunda fase la semana fue bastante más fría en valores absolutos, que la anterior. En la imposibilidad de manejar el clima exterior se pensó en construir un indicador que permitiera "compensar" estas variaciones y se trata más adelante. Por último, cuando el usuario liberó el termostato a demanda de satisfacción térmica de cada integrante de la familia, el consumo fue de $8,18 \mathrm{~m}^{3 /}$ día. Este menor consumo se debe a que los usuarios alcanzan a satisfacer el confort con temperaturas interiores más bajas a lo estipulado en normas.

Figura 11 - Consumo mensual de gas natural entre 2009 y 2014 real (a) y estimado post intervenciones (b)

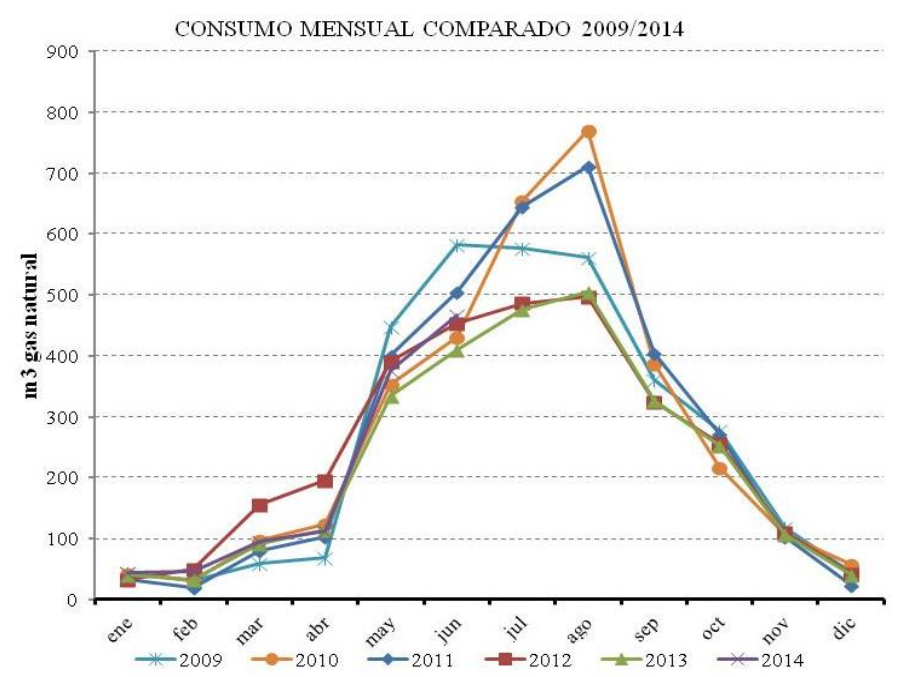

(a) Evolución del consumo de Gas natural de acuerdo con facturas provistas por la empresa Camuzzi

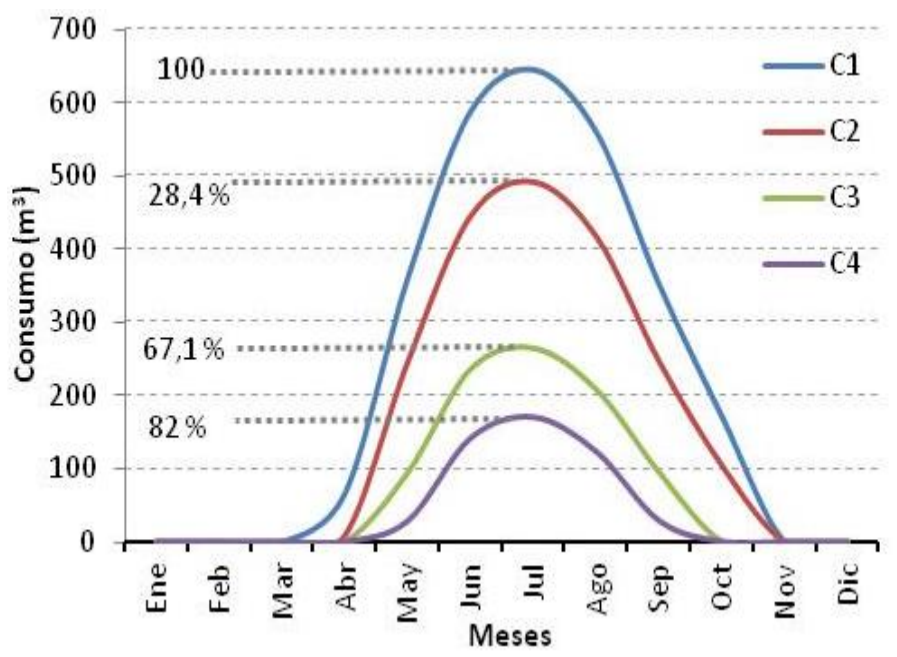

(b) Consumos estimados mediante AuditCad

Nota: Leyenda:

C1 = construcción pre-existente;

$\mathrm{C} 2=\mathrm{C} 1+$ mejoras parciales en muros y techos;

$\mathrm{C} 3=\mathrm{C} 3=$ mejoras totales en muros $\mathrm{y}$ techos; $\mathrm{y}$

$\mathrm{C} 4=\mathrm{C} 3+$ doble vidriado. 
Figura 12 - Consumo mensual de gas respecto de grados día con base $20^{\circ} \mathrm{C}\left(\mathrm{GD}_{20}\right)$ monitoreados

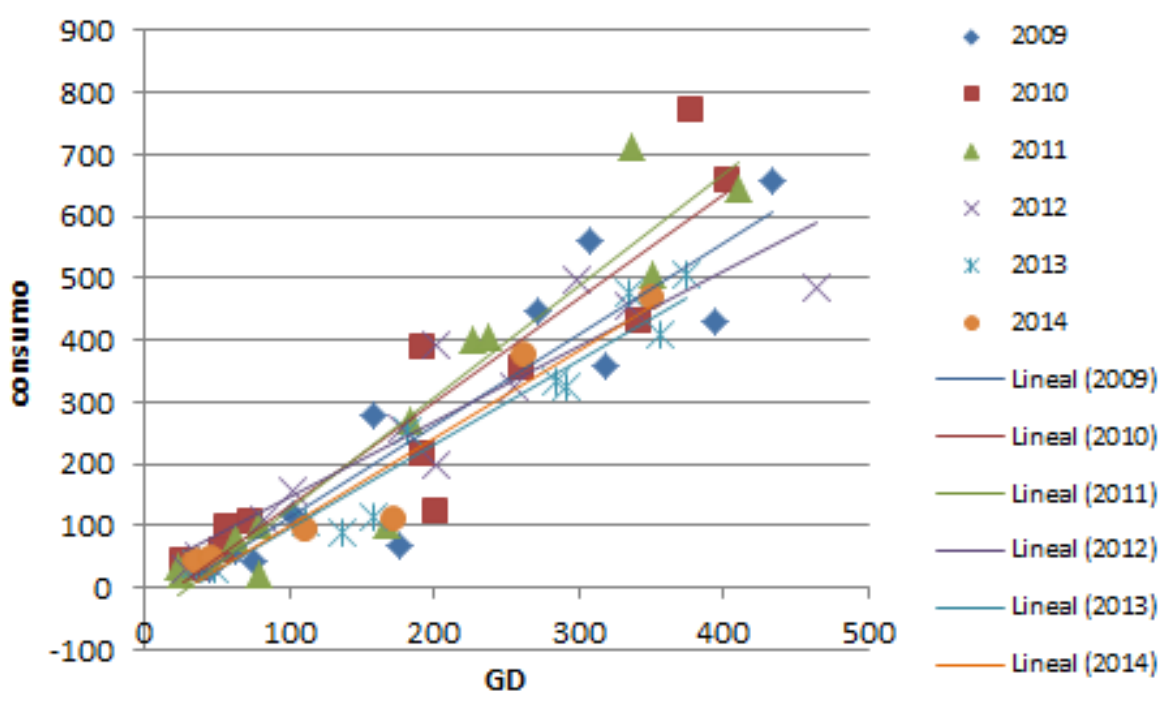

Tabla 1 - Consumo horario comparado

\begin{tabular}{|c|c|c|c|c|c|}
\hline $\begin{array}{c}\text { Mes de } \\
\text { Julio }\end{array}$ & $\begin{array}{l}\text { GD jul } \\
\text { (base } 20^{\circ} \mathrm{C} \\
\text { Gonnet) }\end{array}$ & $\begin{array}{l}\text { Consumo } \\
(\mathrm{m} 3)\end{array}$ & $\begin{array}{c}\text { Consumo p/ } \\
\text { m }^{2} \text { Julio } \\
\left(\mathrm{m}^{3} / \mathrm{m}^{2}\right)\end{array}$ & $\begin{array}{c}\text { Horas } \\
\text { funcionamiento } \\
\text { (estimado) (h) }\end{array}$ & $\begin{array}{c}\text { Consumo } \\
\text { horario } \\
\left(\mathbf{m}^{3} / \mathbf{h}\right)\end{array}$ \\
\hline 2009 & 434 & 576,45 & 3,29 & 248 & 2,32 \\
\hline 2010 & 403 & 655,42 & 3,75 & 248 & 2,64 \\
\hline 2011 & 411 & 644,29 & 3,68 & 248 & 2,60 \\
\hline 2012 & 464 & 486,74 & 2,78 & 248 & 1,96 \\
\hline 2013 & 335 & 476,42 & 2,72 & 248 & 1,92 \\
\hline 2014 & 343 & 497,16 & 2,84 & 744 & 0,67 \\
\hline
\end{tabular}

Tabla 2 - Consumos del mes de julio comparadosen relación a la temperatura de termostato

\begin{tabular}{|c|c|c|c|c|c|}
\hline Período & $\begin{array}{c}\text { Modalidad de } \\
\text { uso }\end{array}$ & $\begin{array}{c}\text { Consumo } \\
\left(\mathrm{m}^{\mathbf{3}}\right)\end{array}$ & $\begin{array}{l}\text { Consumo } \\
\text { diario } \\
\left(\mathbf{m}^{\mathbf{3}} / \text { día }\right)\end{array}$ & $\begin{array}{l}\text { Consumo diario } \\
\text { por superficie } \\
\left(\mathrm{m}^{3} / \mathrm{m}^{2} \text {.día }\right)\end{array}$ & $\begin{array}{c}\text { T media }\left({ }^{\circ} \mathbf{C}\right) \mathbf{y} \\
\text { Desv. estándar } \\
\left({ }^{\circ} \mathbf{C}\right)\end{array}$ \\
\hline $\begin{array}{c}\text { Julio } 2009 \\
\text { (31 días) }\end{array}$ & $\begin{array}{l}\text { Uso cuidado } \\
\text { (8 hs/día) }\end{array}$ & 576,45 & 18,60 & 0,106 & $9^{\circ} \mathrm{C} / 4,38$ \\
\hline $\begin{array}{c}\text { Julio } 2010 \\
\text { (31 días) }\end{array}$ & $\begin{array}{c}\text { Uso cuidado } \\
\text { (8 hs/día) }\end{array}$ & 655,42 & 21,14 & 0,121 & $10^{\circ} \mathrm{C} / 4,44$ \\
\hline $\begin{array}{c}\text { 17-21 Julio } \\
2014 \text { (5 días) }\end{array}$ & $\begin{array}{c}\text { Termost. } 21^{\circ} \mathrm{C} \\
(24 \text { hs/día })\end{array}$ & 76,17 & 15,23 & 0,087 & $12,7^{\circ} \mathrm{C} / 3,53$ \\
\hline $\begin{array}{l}\text { 23-28 Julio } \\
2014 \text { (5 días) }\end{array}$ & $\begin{array}{c}\text { Termost. } 20^{\circ} \mathrm{C} \\
\text { (24 hs/día) }\end{array}$ & 86,39 & 17,28 & 0,099 & $8,0^{\circ} \mathrm{C} / 3,7$ \\
\hline $\begin{array}{c}29 \text { Jul / } \\
4 \text { Ago2014 } \\
\text { (7 días) }\end{array}$ & $\begin{array}{l}\text { Uso libre } \\
\text { (24 hs/día) }\end{array}$ & 57,25 & 8,18 & 0,047 & $15^{\circ} \mathrm{C} / 3,34$ \\
\hline
\end{tabular}

\section{Determinación del nivel de ahorro energético mediante la modificaciónde la temperatura de set point}

Con el objetivo de analizar cómo varía el consumo de energía en calefacción con respecto de la temperatura a la que se fija el termostato de los equipos calefactores se busca verificar la hipótesis de que bajando $1^{\circ} \mathrm{C}$ el termostato en invierno puede generar ahorros del 10\% al 20\% del consumo de calefacción (PRIETO; GIL, 2014).

Para comprobarlo, durante 5 días de la experiencia se fijó el termostato en $21^{\circ} \mathrm{C}$, forzando su encendido y modificando la rutina habitual de los usuarios de climatizar a demanda. Se controló el 
medidor de gas, y pasados los 5 días se cambió a $20^{\circ} \mathrm{C}$ y se dejaron transcurrir dos días completos para reiterar el procedimiento. Durante la primera semana con el termostato a $21^{\circ} \mathrm{C}$ y aplicando la expresión (Ec. 1) se obtuvo un coeficiente de uso de la energía en gas natural (CUE) igual a 8,47 $\mathrm{m}^{3} /{ }^{\circ} \mathrm{C}$. Durante la segunda semana con el termostato a $20^{\circ} \mathrm{C}$ se obtuvo un CUE igual a $7,58 \mathrm{~m}^{3} /{ }^{\circ} \mathrm{C}$.

Por medio de la ecuación 1 se determina el ahorro:

$$
C R U E=\frac{\mathrm{CEPm} 1 /(\mathrm{TT} 1-\mathrm{TE})-\mathrm{CEPm} 2 /(\mathrm{TT} 2-\mathrm{TE} 2)}{\mathrm{CEPm} 1 /(\mathrm{TT} 1-\mathrm{TE} 1)} \times 100
$$

Donde:

CRUE $=$ Coeficiente de reducción de uso de energía (\%);

CEPm1 = Consumo de energía en el período de medición $1\left(\mathrm{~m}^{3}\right)$;

TT1: temperatura de termostato en el período de medición $1\left({ }^{\circ} \mathrm{C}\right)$;

TE1: temperatura exterior media en el período de medición $1\left({ }^{\circ} \mathrm{C}\right)$;

CEPm2: consumo de energía en el período de medición $2\left(\mathrm{~m}^{3}\right)$;

TT2: temperatura de termostato en el período de medición $2\left({ }^{\circ} \mathrm{C}\right)$; y

TE2: temperatura exterior media en el período de medición $2\left({ }^{\circ} \mathrm{C}\right)$.

Durante los 5 primeros días, con el termostato fijado en $21^{\circ} \mathrm{C}$ las 24 horas del día, el consumo de gas total de la vivienda fue de $76,18 \mathrm{~m}^{3} / 5$ días. Pasado el período de dos días de atemperación, los 5 días siguientes con el termostato fijo en $20^{\circ} \mathrm{C}$ el consumo de gas fue de $86.39 \mathrm{~m}^{3} / 5$ días. Es decir que el consumo fue un $13 \%$ superior. Sin embargo la temperatura media en el primer escenario fue de $12,7^{\circ} \mathrm{C}$ y en el segundo la media fue de $8^{\circ} \mathrm{C}$, es decir que fue considerablemente más fría. Para neutralizar el efecto de las temperaturas exteriores se propone la Ecuación 1 para obtener un índice que pueda permitir ser comparado:

$$
\begin{aligned}
& C R U E= \\
& \frac{76,18 \mathrm{~m}^{3} /\left(21^{\circ} \mathrm{C}-12,73^{\circ} \mathrm{C}\right)-86,39 \mathrm{~m}^{3} /\left(20^{\circ} \mathrm{C}-7.97^{\circ} \mathrm{C}\right)}{76,18 \mathrm{~m}^{3}\left(21^{\circ} \mathrm{C}-12,4^{\circ} \mathrm{C}\right)} \times 100
\end{aligned}
$$

$C R U E=\frac{8.856 \mathrm{~m}^{3} /{ }^{\circ} \mathrm{C}-7.183 \mathrm{~m}^{3} /{ }^{\circ} \mathrm{C}}{8.856 \mathrm{~m}^{3} /{ }^{\circ} \mathrm{C}} x 100=0.188 \times 100$

$=18.89 \%$

De esta manera siguiendo el procedimiento (Ec. 2) se observa que el coeficiente de reducción de uso de la energía es del $18.89 \%$ (Ec. 3) bajando en $1^{\circ} \mathrm{C}$ la temperatura de set point del termostato, en invierno en la Ciudad de La Plata.

\section{Ahorro potencial energético en la Ciudad de La Plata}

Se realiza una estimación teórica de la reducción del consumo de energía que implicaría la repetición de la estrategia aplicada en esta vivienda al total de viviendas construidas en el área metropolitana de La Plata. De acuerdo con Rosenfeld, Discoli y Barbero (2003) el perfil de consumo sigue una trayectoria de desarrollo insostenible, con aumento apreciable de consumo en todos los sectores sociales exceptuando los estratos de muy bajos ingresos. Esto motiva a proyectar una estrategia de ahorro en el tipo edilicio "vivienda" apuntando a un grupo socioeconómico consumidor.

Para esto se realizan los siguientes presupuestos.

Se define el edificio "casa" como vivienda con salida directa al exterior, en la que sus moradores no pasan por patios, zaguanes o corredores de uso común (INSTITUTO..., 2001). Este tipo de vivienda, según el Censo 2001 alcanzó para la Ciudad de La Plata el total de 112.365 unidades, para un total de población de 574.369 habitantes. De aquí se desprende que hay una relación de 5,11 habitantes por vivienda. En el Censo 2010 se determina una población de 654.324 habitantes ${ }^{1}$, pero no se censa el tipo de vivienda. Estimando que la proporción de habitantes por vivienda se mantiene constante, el conjunto de viviendas "tipo casa" estaría compuesto por 128.048 unidades a 2010.

La vivienda tipo se considera como un prisma de $60 \mathrm{~m}^{2}$, de $8,66 \mathrm{~m}$. de frente por 7 de fondo y 3 metros de altura interior, siendo su superficie envolvente $60 \mathrm{~m}^{2}$ de cubierta y $94 \mathrm{~m}^{2}$ de muros. El costo del reciclaje energético de las viviendas será de $\$ 232 / \mathrm{m}^{2}$ para cubiertas y $\$ 258 / \mathrm{m}^{2}$ para muros, es decir, el costo que implicó la mejora en el caso de analizado. Entonces la inversión por vivienda será de \$38.172, o su equivalente en dólares US\$ 4.400 (para US\$ $1=\$ 8,70$ )

El consumo energético para calefacción de la vivienda analizada sin aislar simulado es de 2890 $\mathrm{m}^{3} / \mathrm{año}$; mientras que el consumo de la misma vivienda con las mejoras es $2070 \mathrm{~m}^{3} /$ año. La vivienda analizada tiene $175 \mathrm{~m}^{2}$ mientras que la propuesta para la extrapolación tiene $60 \mathrm{~m}^{2}$, por lo que proporcionalmente se estima una demanda de

${ }^{1}$ Cuadro P5-D. Provincia de Buenos Aires, partido La Plata. Población total por país de nacimiento, según sexo y grupo de edad. Año 2010. 
$990 \mathrm{~m}^{3}$ de gas para la vivienda convencional y 709 $\mathrm{m}^{3}$ para la vivienda mejorada.

Este cálculo indica que si se invirtieran $\$ 38.172$ por vivienda (US\$ 4.400), el consumo de gas en calefacción se reduciría al $44 \%$ en la extrapolación al total de La Plata.

Esto nos indica que en el caso hipotético de reciclar el $100 \%$ de las viviendas de La Plata, y tomando como tamaño estándar $60 \mathrm{~m}^{2}$ se podrían ahorrar 30.313 toneladas de petróleo equivalente al año en gas para calefacción, como se muestra en la Tabla 3. Este ahorro supone la inversión de US\$ 563.411.200 para lograr el aislamiento propuesto.

Según el Balance Energético Nacional, en 2013 el sector residencial argentino consumió 15.626.000 TEP, de lo que se estima que 242.203 TEP fueron consumidos en La Plata, por lo que el ahorro potencial en la región alcanza el 12\% del consumo, reduciendo la calefacción.

En la Figura 13 se muestra un plan progresivo de reciclaje de viviendas a 10 años, aplicando al $10 \%$ de las viviendas cada vez, a 20 años, y la situación sin intervenir. Podemos evaluar el costo de demorar la intervención en las viviendas, ya que más de 2,5 millones de TEP podrían ahorrarse en los 20 años de implementación (Figura 14).

\section{Conclusiones}

El trabajo permitió evaluar el comportamiento térmico del reciclado energético de una vivienda en condiciones reales de uso, como ejemplo de vivienda ubicada en área suburbana de baja densidad en proceso de consolidación, de baja altura, generalmente despegadas del perímetro del lote. Se analizaron tres intervalos de tiempo con diferentes premisas para observar su comportamiento térmico y energético y poder compararlos entre sí y con periodos anteriores.

El cálculo de consumo de gas mensual en función de los grados días de calefacción con base $20^{\circ} \mathrm{C}$ permite verificar si existen disfunciones en la envolvente $\mathrm{o}$ en comportamiento del usuario respecto de otras regiones así como determinar el umbral de consumo para la categoría de usuario en el país, de acuerdo como proponen Gil y Prieto (2013).

Tabla 3 - Cálculo de ahorro estimado reciclando el total de viviendas de La Plata

\begin{tabular}{|c|c|c|c|c|c|}
\hline TIPO & $\begin{array}{c}\$ \\
\text { Sobrecosto }\end{array}$ & $\begin{array}{c}\text { Consumo } \\
175 m^{2} \\
\left(\mathbf{m}^{3} / \mathbf{a n ̃ o}\right)\end{array}$ & $\begin{array}{c}\text { Consumo } \\
60 \mathbf{m}^{2} \\
\left(\mathrm{~m}^{3} / \mathrm{añ} 0\right)\end{array}$ & $\begin{array}{c}\text { Consumo La } \\
\text { Plata } \\
\left(\mathrm{m}^{3} \mathrm{x}\right. \\
128.048 \mathrm{viv})\end{array}$ & $\begin{array}{c}\text { Consumo en TEP } \\
(\mathrm{TEP}= \\
\left.1187 \mathrm{~m}^{3} \mathrm{GN}\right)\end{array}$ \\
\hline CONVENCIONAL & $\$ 0$ & 2890 & 990 & 126.767 .520 & 106.796 \\
\hline $\begin{array}{c}\text { CON } \\
\text { RECICLADO } \\
\text { ENERGÉTICO }\end{array}$ & US\$ 4.400 & 2070 & 709 & 90.786 .032 & 76.483 \\
\hline
\end{tabular}

Figura 13 - Demanda de TEP para calefacción en viviendas de la Ciudad de La Plata - proyección a 20 años según plan de intervención

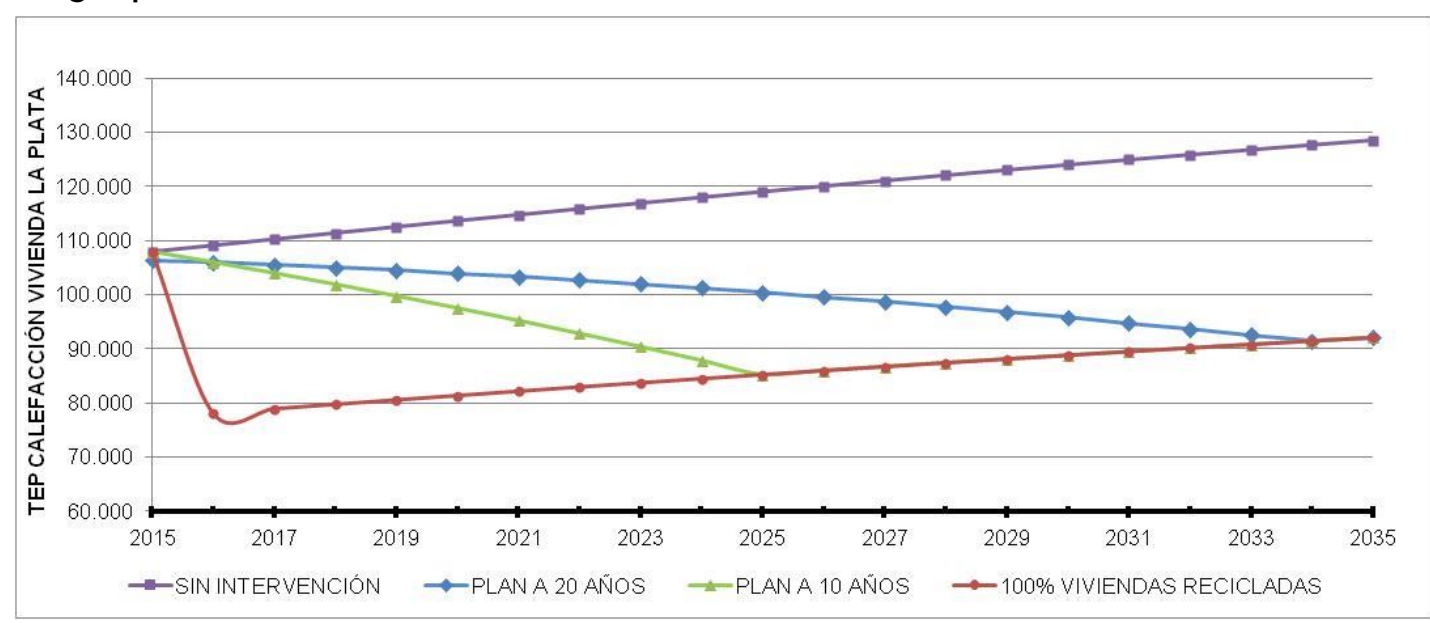

Impacto de la envolvente en la demanda de energía en calefacción residencial de la región metropolitana de La 
Figura 14 - Ahorro acumulado de TEP para calefacción en viviendas de la Ciudad de La Plata proyección a 20 años

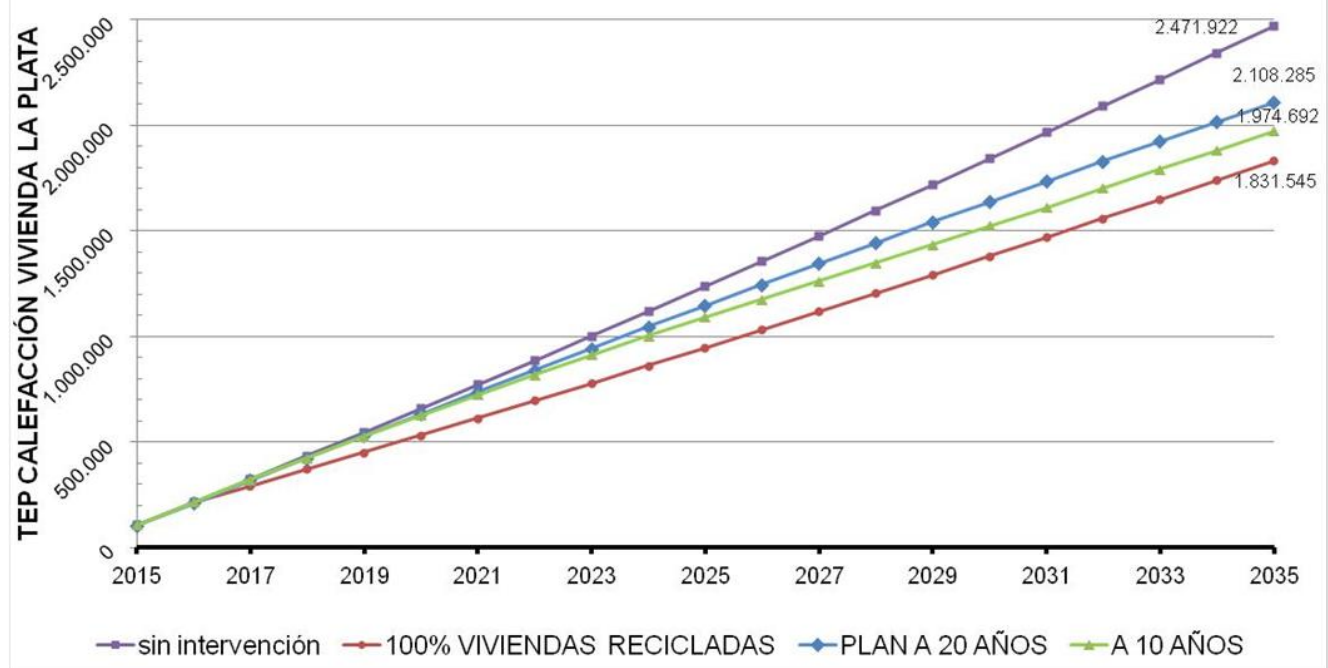

De acuerdo con lo observado en la realización de este trabajo, podemos concluir que la mejora realizada mediante el sistema EIFS es efectiva, rápida en su ejecución, y una excelente alternativa para mejorar una vivienda post facto.

A partir de la mejor resistencia térmica de la envolvente el usuario mejoró el confort térmico independientemente del sistema de calefacción, que trabaja a menor temperatura de termostato y durante menos tiempo. La vivienda deja de ser energo-dependiente para ser habitable con la ganancia solarque el partido arquitectónico facilita. El modelo realizado con AuditCad y EnergoCad prediceun ahorro del $28 \%$ en calefacción, dato que puede verificarse parcialmente observando la reducción mostrada en la auditoría energética realizada.

El trabajo permitió corroborar la hipótesis propuesta por Prieto y Gil (2014) respecto al importante ahorro $(18,89 \%)$ que genera reducir en un grado la temperatura de termostato de $21^{\circ} \mathrm{C}$ a $20^{\circ} \mathrm{C}$. Pero entendemos que sin mejora térmica en la envolvente esto no es posible ya que en años previos el usuario debía fijar en $24^{\circ} \mathrm{C}$ el termostato para obtener un confort térmico deficiente con alto consumo de energía específico. Esta salvedad es importante ya que de proponerse a la sociedad la recomendación de bajar un grado el termostato para edificios que cuenten con climatización central, sóloserá efectivoenenvolventes que cuenten con suficiente nivel de aislamiento térmico a fin de aumentar la temperatura superficial interior en cerramientos opacos y transparentes.
Para esto entendemos debe superarse el Nivel B propuesto por la Norma IRAM 11605 y tender a acercarse al Nivel A.

Un $60 \%$ del volumen de gas que se estima que actualmente se consume en calefacción podría ser utilizado para fines productivos, para ampliar la red a mayor cantidad de usuarios residenciales; o simplemente reducir las emisiones de $\mathrm{CO}_{2}$ que implican el uso de gas.

Se propone una proyección de ahorro energético en la región a 20 años (Figura 14), con la hipótesis de que el total de las viviendas incorporan aislación térmica mediante la tecnología propuesta con un costo de US\$ 4.400 en tres escenarios:

(a) el $100 \%$ en el primer año;

(b) reciclaje progresivo del $10 \%$ de las viviendas los 10 primeros años y luego el mantenimiento según la tasa de crecimiento de las viviendas; $y$

(c) por último la mejora del 5\% de las viviendas por año, completando el total a 20 años.

El ahorro acumulado luego de 20 años es de 640 mil TEP en el primer caso, 497 mil en el segundo y 363 mil en el tercero. Dicha estimación se realiza bajo el supuesto de que el promedio de superficie de todas las viviendas es de $60 \mathrm{~m}^{2}$ y que el tipo edilicio crece de manera constante.

El $12 \%$ de ahorro de energía en calefacción al año no es el único beneficio, sino que la generación de empleo y la demanda de materiales de industria nacional tienen una incidencia positiva en el rubro de la construcción. 
A pesar dela tendencia actual hacia lo sustentable y energéticamente eficiente, es el desconocimiento de los profesionales lo que dificulta la ejecución de aislaciones térmicas adicionales, y no el presupuesto económico. Esto debido principalmente a que en la formación de los que poseen la incumbencia en la construcción de edificios (arquitectos, ingenieros y técnicos) no se trata en la currícula de forma obligatoria el uso racional de energía y/o la eficiencia energética edilicia.

\section{Referencias}

BOURGES, C.; GIL, S. Amortización del Costo de Mejoras en la Aislación Térmica de las Viviendas. Petrotecnia, v. 55, n. 1, p. 72-78. 2014.

BUENOS AIRES. Decreto Reglamentario 1030, de 2 de julio de 2010, que aprueba la reglamentación de la Ley $\mathrm{N}^{\circ} 13059$ sobre "Condiciones de acondicionamiento térmico exigibles en la construcción de edificios. Disponíble en: <http://www.gob.gba.gov.ar/dijl/index.php?var=63 528\&out=1\&recurso=1>. Acceso en: 03 nov. 2015.

BUENOS AIRES. Ley 13059, condiciones de acondicionamiento térmico exigibles en la construcción de edificios para una mejor calidad de vida y disminución del impacto ambiental. Municipios: autoridad de aplicación. 2003. Disponíble en:

<.http://www.gob.gba.gov.ar/dijl/index.php?var=6 $3528 \&$ out $=1 \&$ recurso $=1 \# 13059>$. Acceso en: 03 nov. 2015.

CZAJKOWSKI, J. et al. Evaluación del Confort Higrotérmico Invernal en Viviendas Unifamiliares del Gran La Plata Mediante Auditorías. Avances en Energías Renovables y Medio Ambiente, v. 16, p. 5.101-5.106, 2012.

CZAJKOWSKI, J. Programa AuditCad Para el Análisis del Comportamiento Energético Edilicio Basado en Auditorías Energéticas y de Confort. In: ENCONTRO DE CONFORTO NO AMBIENTE CONSTRUIDO, 5., Gramado, 1999. Anais... Gramado: ANTAC, 1999.

CZAJKOWSKI, J.; CORREDERA, C.; SAPOSNIK, M. Análisis de la Relación Entre Demanda de Gas Natural en Calefacción Según "Energocad" y Consumos Reales en Viviendas Unifamiliares del Gran La Plata. Avances en Energías Renovables y Medio Ambiente, v. 7, p. 7.13-7.17, 2003.
FILIPPÍN, C.; FOLLARI, J. Comportamiento Termico de un Proyecto Demostrativo Bioclimático en San Luis. Avances en Energías Renovables y Medio Ambiente, v. 13, p. 5.695.76, 2003.

GELARDI, D.; ESTEVES, A. Relación Entre la Ganancia Solar y la Calefacción Auxiliar Para dos Tipos de Envolvente Formal Edilicia. Avances en Energías Renovables y Medio Ambiente, v. 14, p. 33-40, 2010.

GIL, S. ¿Cómo Se Distribuye el Consumo Residencial de Gas? Modos de promover un uso más eficiente. Petrotecnia, v. 54, n. 6, p. 86-93, dic. 2013.

GIL, S.; PRIETO, R. Categorización Racional de Usuarios Residenciales: herramientas para promover un uso más eficiente del gas. Avances en Energías Renovables y Medio Ambiente, p. 15-24, 2013.

GONZALO, G. E. Manual de Arquitectura

Bioclimática. Buenos Aires, 2003. Librería Técnica CP67.

GOOGLE MAPS. [Imagem]. Disponible en: <https://www.google.com.ar/maps/@ 34.8704373,-58.0143724,17.96z>. Acceso en: 14 jul. 2014.

INSTITUTO NACIONAL DE ESTADÍSTICA Y CENSOS. Informe de Viviendas del Censo Nacional de Población, Hogares y Viviendas del año 2001. 2001. Disponíble en:

<http://www.indec.gov.ar/micro_sitios/webcenso/ >. Acceso en: 03 nov. 2015.

INSTITUTO ARGENTINO DE

NORMALIZACIÓN Y CERTIFICACIÓN.

IRAM 11603: acondicionamiente térmica de edificios: clasificación bioambiental de la República Argentina. Buenos Aires, 2012.

OLGYAY, V. Design With Climate. Princeton: Princeton University Press, 1963.

OVIEDO, J. Energía: en un mes importaron de Uruguay más que en todo 2013. La Nación [en línea]. Buenos Aires, 30 julio 2014. Disponible en: $<$ http://www.lanacion.com.ar/1714152-energia-enun-mes-importaron-de-uruguay-mas-que-en-todo2013>. Accesso en: 11 dic. 2015.

PRIETO, R.; GIL, S. Regulación del Termostato: un modo simple y racional de ahorrar energía en calefacción y refrigeración. Petrotecnia, p. 102109, dic. 2014. 
ROSENFELD, E.; DISCOLI, C.; BARBERO, D. El Consumo de Energía en el Área Metropolitana de Buenos Aires en la Década del '90: una trayectoria de desarrollo insustentable. Avances en Energías Renovables y Medio Ambiente, v. 7, n. 1, p. 07.01-07.06, 2003.

SALVETTI, M. B.; CZAJKOWSKI, J. D.; GÓMEZ, A. F. Análisis del Comportamiento Energético-Ambiental en Torre de viviendas en La Plata. Avances en Energías Renovables y Medio Ambiente, v. 13, p. 5.127-5.133, 2009.

STAZI, F.; DI PERNA, C.; MUNAFÓ, P. Durability of 20-Year-Old External Insulation and Assessment of Various Types of Retrofitting to Meet New Energy Regulations. Energy and Buildings, v. 41, n. 7, p. 721-731, 2009.
TANIDES, G. C. et al. Calefacción en el Sector Residencial Argentino: primera modelización y estudio de las consecuencias de la sustitución de bombas de calor en reemplazo de calefactores a gas. In: ENCUENTRO LATINOAMERICANO DE USO RACIONAL Y EFICIENTE DE LA ENERGÍA, Buenos Aires, 2013. Proceedings... Buenos Aires, 2013.

VERBEEK, G.; HENS, H. Energy Savings in Retrofitted Dwellings: economically viable? Energy and Buildings, v. 37, n. 7, p. 747-754, 2005.

YAÑEZ, G. Energía Solar, Edificación y Clima. Madrid: MOPU, 1982. v. 1.

María de la Paz Diulio

Laboratorio de Arquitectura y Hábitat Sustentable, Facultad de Arquitectura y Urbanismo | Universidad Nacional de La Plata | Calle 47m 162 | La Plata - Argentina | 1900 | Tel. +54 (0221) 423-6587 Int. 255 | E-mail: diuliomp@gmail.com

\section{Gabriela Reus Netto}

Laboratorio de Arquitectura y Hábitat Sustentable, Facultad de Arquitectura y Urbanismo | Universidad Nacional de La Plata | E-mail: gabi_reus@hotmail.com

\section{Roberto Berardi}

Laboratorio de Arquitectura y Hábitat Sustentable, Facultad de Arquitectura y Urbanismo | Universidad Nacional de La Plata | E-mail: berardiroberto@hotmail.com

\section{Jorge Daniel Czajkowski}

Laboratorio de Arquitectura y Hábitat Sustentable, Facultad de Arquitectura y Urbanismo | Universidad Nacional de La Plata |

E-mail: czajko@yahoo.com

\section{Revista Ambiente Construído}

Associação Nacional de Tecnologia do Ambiente Construído

Av. Osvaldo Aranha, $99-3^{\circ}$ andar, Centro

Porto Alegre - RS - Brasil

CEP $90035-190$

Telefone: +55 (51) 3308-4084

Fax: +55 (51) 3308-4054

www.seer.ufrgs.br/ambienteconstruido

E-mail: ambienteconstruido@ufrgs.br

70 Diulio, M. de la P.; Reus Netto, G.; Berardi, R.; Czajkowski, J. D. 